\title{
IMPACT OF COUNSELING ON IMPROVING ADHERENCE TO DYSLIPIDEMIA PATIENT
}

\author{
SARU NOLIQO RANGKUTI, AZIZAH NASUTION*, KHAIRUNNISA
}

Department of Pharmacology, Faculty of Pharmacy, Universitas Sumatera Utara, Jalan Almamater, USU-Kampus, Medan 20155, Indonesia. Email: nasution.azizah4@gmail.com

Received: 07 March 2018, Revised and Accepted:25 March 2018

ABSTRACT

Objective: The objective of this study was to determine the impact of counseling on adherence of dyslipidemia outpatients to the prescribed medications in An-Nisa Hospital Tangerang period July 2016-November 2016

Methods: This prospective a quasi-experimental design with pre- and post-test design was done to analyze the impact of counseling in An-Nisa Hospital Tangerang. Patients' characteristics were statistically analyzed using Chi-square. The patient adherence toward therapy was analyzed using Morisky Medication adherence scale-8.

Results: The present study indicated that most of the patients $(70 \%)$ were females with ages: $>50.70 \%$; $\leq 50.30 \%$. The counseling significantly affected the adherence level on dyslipidemia patients, $\mathrm{p}<0.001$.

Conclusion: This research proved that counseling had a positive impact on the patients' adherence.

Keywords: Dyslipidemia, Counseling, Adherence, Morisky medication adherence scale-8.

(C) 2018 The Authors. Published by Innovare Academic Sciences Pvt Ltd. This is an open access article under the CC BY license (http://creativecommons. org/licenses/by/4. 0/) DOI: http://dx.doi.org/10.22159/ajpcr.2018.v11s1.26556

\section{INTRODUCTION}

Dyslipidemia is a condition in which there is an elevated concentration of total cholesterol, low-density lipoprotein, high-density lipoprotein, and triglycerides in the body. These conditions can subsequently lead to plaque formation at the specific sites of the arterial walls which further result in luminal narrowing. This process is called as atherosclerosis. Blood vessels constriction will cause bloodstream getting slowed even blocked, so the bloodstream in coronary blood vessels which function to provide $\mathrm{O}_{2}$ for heart is decreased. Atherosclerosis is one of the causes of cardiovascular disease (CVD) [1]

CVD is the main cause of death in the world. It has been found there approximately 17 million deaths worldwide are caused by CVD in 2008 (30\% of deaths in the world) [2]

The pharmacists practice activity classification developed in 1998 by the American Pharmaceutical Association describes pharmacist's activities, including many tasks that involve patient interaction, such as interviewing the patient, obtaining patient information, educating the patient, providing verbal and written information, discussing, demonstrating, face-to-face patient contact, and patient counseling [3].

Patient counseling is defined as "providing medication information orally or in written form to the patients or their representatives on directions of use, advice on side effects, precautions, storage, diet, and lifestyle modifications" [4].

In the practice philosophy of pharmaceutical care, pharmacist is responsible directly to the patients they serve. From this patientcentered view, patient counseling improves patient care. From the pharmacist's point of view, it is integral to providing competitive and professional pharmacy service. It is evident that patient counseling and patient-pharmacist interaction are key to the pharmacist's role today [3].

Based on the orientation changes, pharmacists are required to improve their knowledge, skill, and behavior so that they can conduct direct interaction with the patient. The interaction forms consist of implementing the information provision, monitoring the drug utilization and knowing the final purpose as expected and well documented. Pharmacists must understand and be aware of the possibilities of medication errors in the process of health care.

Many factors are associated with dyslipidemia including lifestyle behavior, genetic factor, alcohol, cigarette, age, and gender. According to the Indonesian Society of Endocrinology (PERKENI) which also refers to the guidelines for the National cholesterol education program adult treatment panel III, the hypercholesterolemia management in Indonesia includes non-pharmacological therapy called therapeutic lifestyle change (TLC) and pharmacological therapy utilize cholesterol reduction drugs [5].

Adherence to prescribed medication is required in dyslipidemia drugs utilization to achieve the target therapy. However, non-adherence to drug therapy is a problem faced by many patients with chronic conditions. Based on the World Health Organization report in 2003, average patients adherence level on chronic disease in advanced countries is only $50 \%$, while in develop countries the number even lower. The result of survey that conducted in eight countries of Asia includes Indonesia in the study of Pan-Asian Centralized Pan-Asian survey on the undertreatment of hypercholesterolemia (Cepheus) states that $68.7 \%$ patients fail to achieve the target therapy and $65 \%$ patients admitted to forget to consume cholesterol reduction drugs several times. It is one of the causes of failed hypercholesterolemia therapy in further would become CVD [6]. In relation to the problems, this research was conducted to study the counseling effect toward patient adherence level in therapy.

\section{METHODS}

\section{Study design}

This study was conducted using quasi-experimental with pre- and postdesign at Hospital An-Nisa Tangerang from July to November 2016. The respondents consist of 30 patients with the inclusion criteria. Patient's adherence level data were obtained using Morisky Medication Adherence Scale (MMAS-8) questionnaire score. The MMAS-8 scores 
ratings were divided into three categories, low adherence with the score more than 2, moderate adherence score 1-2, and high adherence with the score 0 . Thus, the higher the score MMAS-8 indicated low adherence toward treatment.

\section{Statistical analysis}

Data were tested normality distribution using Kolmogorov-Smirnov test. The parametric test was used if the data were normally distributed. Patient characteristics were statistically analyzed using the Chi-square test. Interval data or ratio shown in the form of mean and analyzed using an independent t-test to compare before and after the intervention.

\section{RESULTS}

\section{Patients characteristics}

The number of patients who participated in this study consisted of 30 . Based on gender, most (70\%) of the dyslipidemia patients were female. Dyslipidemia was more prevalent in female compared to male, $\mathrm{p}=0.028$. By age, the majority (70\%) of the dyslipidemia patients were at the age of 50 years or higher. The rest (30\%) of the patients were at the age of below 50 years. This study found that the prevalent of dyslipidemia was associated with age, $p=0.028$. Data characteristics of the patients are shown in Table 1.

\section{Counseling effect toward adherence level}

The average score of dyslipidemia patients' adherence level for the control group based on MMAS-8 was $3.90 \pm 1.32$ and included into low adherence, while the score for the experimental group was $1.90 \pm 1.24$ categorized into moderate adherence; there was statistically significant difference between the scores of these two groups of patients $(\mathrm{p}<0.001)$ as shown in Table 2.

\section{DISCUSSION}

\section{Patients characteristics}

Most of the patients $(70 \%)$ were females with ages: $>50,70 \%$; $\leq 50$, $30 \%$. The study of estrogen changing in women who experience menopause revealed that the prevalence of women who had experienced menopause is vulnerable to increase the cholesterol level. It is caused by the normal production of estrogen during the menstrual cycle and decreases after menopause (Sakuma and Kitabatake, 2002). Based on previous studies that had been conducted found that there is a significant correlation between age and cholesterol levels in the blood. It can be caused by the body's functions that are already decreased in patients who already $>50$ years. As a result, the body's ability to process food is decreasing, so it is interrupting the body metabolism [7].

Many studies have demonstrated the effectiveness of pharmacists provision of information and reminders. For example, a study in Memphis Tennessee found adherence rates of $84.7 \%$ for patients receiving a high level of information about the antibiotic drug, compared with $63 \%$ for patients receiving less information. Another study improved adherence to cardiac, antihypertensive, and oral hypoglycemic medications by $49 \%$ through a prescription reminder system. The most important role of patient counseling is to improve the quality of life and provide quality care of patients. It is accepted that patient counseling and education helps in promoting the rational use of medicines which can lead to successful therapeutic outcomes [8]. In addition, a study conducted on 76 national community pharmacies in the US indicated that face-to-face counselling demonstrated greater medication adherence [9]. Another study conducted in four primary health centers in Indonesia also indicated that counselig improved the outcomes of hypertensive patients [10]. Counseling can have a significant impact to improve patients adherence.
Table 1: Patients characteristics

\begin{tabular}{llll}
\hline No & Characteristics & Patients n=30 (\%) & $\mathbf{p}$ \\
\hline 1 & Sex & & 0.028 \\
& Male & $9(30)$ & \\
& Female & $21(70)$ & 0.028 \\
2 & Age (years) & $21(70)$ & \\
& $>50$ & $9(30)$ & \\
& $\leq 50$ &
\end{tabular}

Table 2: Average scores of patients adherence

\begin{tabular}{llll}
\hline Variable & Control & Treatment & $\mathbf{p}$ \\
\hline $\begin{array}{l}\text { Patients adherence } \\
\text { level average scores }\end{array}$ & $3.90 \pm 1.32$ & $1.90 \pm 1.24$ & $<0.001$ \\
\hline
\end{tabular}

\section{Counseling effect toward adherence level}

The principal treatment of hypercholesterolemia not only includes pharmacological therapy but also non-pharmacological therapy called TLC. Pharmacists are part of a medical staff that has a strategic role to improve the patient adherence to drug therapy that had been given and to implement a healthy lifestyle [6].

\section{CONCLUSION}

Counseling affected the adherence dyslipidemia patients to their medications. Treatment of dyslipidemia patients at Hospital An-Nisa Tangerang with counseling was more adherent to therapy compared to those without counseling. This research proved that counseling had a positive impact on the patients' adherence to their medications. This research proved that counseling had a positive impact on the patients' adherence.

\section{REFERENCES}

1. Dalal D, dan Robbins JA. Management of hyperlipidemia in the elderly population: An evidence-based approach. South Med J 2002;95:61.

2. World Health Organization. About Cardiovascular diseases. World Health Organization; 2013. Available from: http://www. who.int/cardiovascular diseases/about cvd/en/. [Last accessed on 2016 Apr 15]

3. Rantucci MJ. Pharmacist Patient Counseling. $2^{\text {nd }}$ ed. Jakarta: EGC; 2007. p. 86-93.

4. Palaian S, Prabhu M, Shankar PR. Patient counseling by pharmacist-a focus on chronic illness. Pak J Pharm Sci 2006;19:65-72.

5. Grundy S, Cleeman J, Merz C, Brewer HB Jr., Clark LT, Hunninghake DB, et al. Implications of recent clinical trials for the national cholesterol education program adult treatment panel III guidelines. Circulation 2004;110:227-39.

6. Yeaw J, Benner JS, Walt JG, Sian S, Smith DB. Comparing adherence and persistence across 6 chronic medication classes. J Manag Care Pharm 2009;15:728-40.

7. Sakuma I, Kitabatake A. Hormone replacement therapy (HRT) for hyperlipidemia after menopause. Nihon rinsho. Jpn J Clin Med 2002;60(5):1025-31.

8. Hussain A, Ibrahim MI, Baber ZU. Using the potentials of community pharmacies to promote rational drug use in Pakistan: An opportunity exists or lost? J Pak Med Assoc 2012;62:1217-22.

9. Taitel M, Jiang J, Rudkin K, Ewing S, Duncan I. The impact of pharmacist face-to-face counseling to improve medication adherence among patients initiating statin therapy. Patient Prefer Adherence 2012;6:323-9.

10. Nasution A, Tanjung HR. Impacts of counseling on adherence to prescribed medications and blood pressure of hypertensive patients in four Indonesian primary health centers. Int J Pharm Pharm Sci 2015;7:114-7 